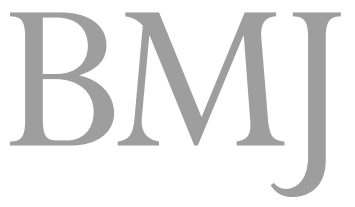

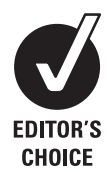

The full version of this article is available from BJSM online at http://bism.bmj. com/cgi/content/full/43/3

${ }^{1}$ School of Health and Rehabilitation Sciences, University of Queensland, Brisbane, Australia 4072

${ }^{2}$ Melbourne School of Engineering, University of Melbourne, Australia

${ }^{3}$ Queensland Clinical Trials Centre, School of Population Health, University of Queensland

${ }^{4}$ Gait Research Laboratory, Department of Physical Therapies, Northern Arizona University, USA Correspondence to: B Vicenzino b.vicenzino@uq.edu.au

Reproduced with permission from BM/ 2008;337:a1735 doi:10.1136/bmi.a1735

\title{
Foot orthoses and physiotherapy in the treatment of patellofemoral pain syndrome: randomised clinical trial
}

\author{
Natalie Collins, PhD candidate, ${ }^{1}$ Kay Crossley, principal research fellow, ${ }^{2}$ Elaine Beller, director, \\ biostatistics, ${ }^{3}$ Ross Darnell, statistician, ${ }^{1}$ Thomas McPoil, regents professor, ${ }^{4}$ Bill Vicenzino, head of \\ division, physiotherapy ${ }^{1}$
}

\section{ABSTRACT}

Objective To compare the clinical efficacy of foot orthoses in the management of patellofemoral pain syndrome with flat inserts or physiotherapy, and to investigate the effectiveness of foot orthoses plus physiotherapy.

Design Prospective, single blind, randomised clinical trial. Setting Single centre trial within a community setting in Brisbane, Australia.

Participants 179 participants (100 women) aged 18 to 40 years, with a clinical diagnosis of patellofemoral pain syndrome of greater than six weeks' duration, who had no previous treatment with foot orthoses or physiotherapy in the preceding 12 months.

Interventions Six weeks of physiotherapist intervention with off the shelf foot orthoses, flat inserts, multimodal physiotherapy (patellofemoral joint mobilisation, patellar taping, quadriceps muscle retraining, and education), or foot orthoses plus physiotherapy.

Main outcome measures Global improvement, severity of usual and worst pain over the preceding week, anterior knee pain scale, and functional index questionnaire measured at 6, 12, and 52 weeks.

Results Foot orthoses produced improvement beyond that of flat inserts in the short term, notably at six weeks (relative risk reduction $0.66,99 \%$ confidence interval 0.05 to 1.17 ; NNT 4 (99\% confidence interval 2 to 51 ). No significant differences were found between foot orthoses and physiotherapy, or between physiotherapy and physiotherapy plus orthoses. All groups showed clinically meaningful improvements in primary outcomes over 52 weeks.

Conclusion While foot orthoses are superior to flat inserts according to participants' overall perception, they are similar to physiotherapy and do not improve outcomes when added to physiotherapy in the short term management of patellofemoral pain. Given the long term improvement observed in all treatment groups, general practitioners may seek to hasten recovery by prescribing prefabricated orthoses.

Trial registration Australian Clinical Trials Registry ACTRN012605000463673 and ClinicalTrials.gov NCT00118521.

\section{INTRODUCTION}

Patellofemoral pain syndrome, or idiopathic pain arising from the anterior knee, ${ }^{1}$ is one of the most common musculoskeletal presentations to general practice $^{2}$ and sports medicine clinics. ${ }^{3-8}$ In a retrospective survey of 2002 runners presenting to a sports medicine centre, patellofemoral pain syndrome accounted for $19 \%$ of running injuries, ${ }^{9}$ whereas a two year prospective cohort study reported onset of the syndrome in $9 \%$ of 282 students of physical education aged $17-21 .^{10}$ The pain is characteristically provoked by activities such as squatting, stair walking, and running, and hence impacts on many aspects of daily life, including the ability to perform pain free exercise or work related activities. Patellofemoral pain syndrome can result in repeat visits to a doctor given its tendency towards chronicity, with 94\% of patients continuing to experience pain up to four years after initial presentation and $25 \%$ reporting significant symptoms up to 20 years later. ${ }^{11}$

Despite the prevalence, chronicity, and impact of patellofemoral pain syndrome, several systematic reviews of interventions attest to a dearth of high quality research on management. ${ }^{12-17}$ One study concluded that the available evidence at that time would lead the practitioner to implement a programme of education, stretching, and strengthening of the thigh muscles, and possibly foot orthoses. ${ }^{15}$ Subsequently a high quality randomised controlled trial found that a multimodal physiotherapy programme for six weeks ${ }^{18}$ was more effective than sham treatment: relative risk of noticeable improvement 3.39 (95\% confidence interval 1.69 to 6.80$).{ }^{19}$ That study did not, however, compare physiotherapy with the control sham intervention beyond six weeks.

As an alternative or adjunct to physiotherapy, foot orthoses are commonly used to treat active people with patellofemoral pain syndrome. Recently, a systematic review of the clinical efficacy of foot orthoses identified two small clinical trials in people with patellofemoral pain syndrome. ${ }^{20}$ These studies suggest that foot orthoses may be of benefit. ${ }^{2122}$ No high quality randomised controlled trials have evaluated the use of foot orthoses for treating patellofemoral pain 
syndrome in the short or long term. Evidence to guide the use of foot orthoses for this common clinical condition is imperative considering the widespread use of foot orthoses and the lack of consensus and controversy surrounding their prescription. ${ }^{2324}$

We evaluated the short and long term clinical efficacy of prefabricated foot orthoses in the treatment of patellofemoral pain syndrome compared with flat inserts or physiotherapy alone, and evaluated whether orthoses improved the effects of physiotherapy. We hypothesised that foot orthoses would be superior to flat inserts and equivalent to physiotherapy and that the combination of foot orthoses and physiotherapy would be superior to physiotherapy alone.

Telephone screening $(n=1530)$

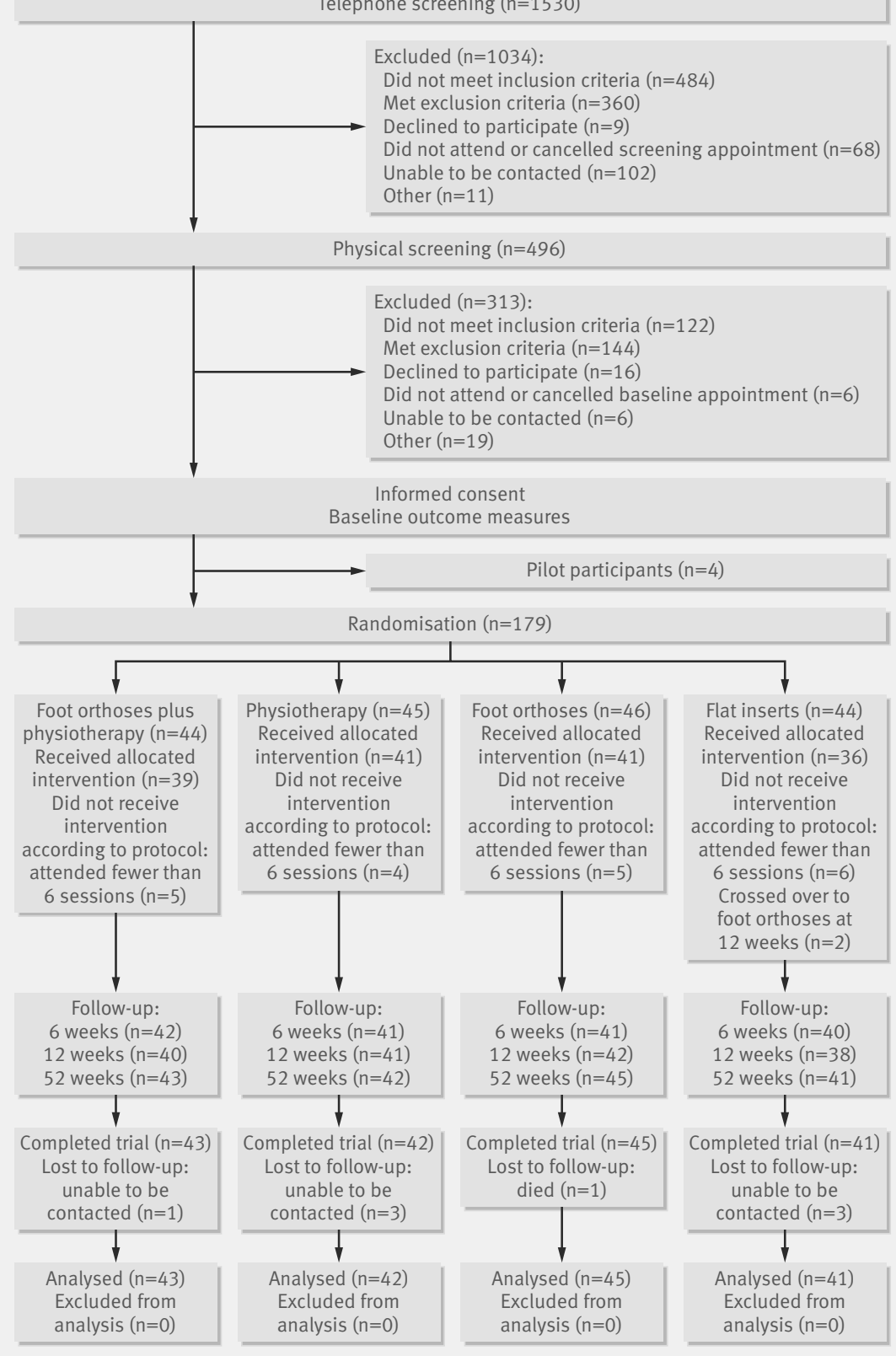

Fig 1| Flow of participants through study

\section{METHODS}

We carried out a pragmatic, single blind, randomised clinical trial in a community setting for 12 months. The methods have been described in detail previously. ${ }^{25}$

Volunteers from the greater Brisbane, Gold Coast, and Toowoomba regions of Queensland, Australia responded to advertisements in print media, radio and television media releases, noticeboards, and referrals from practitioners. Eligibility criteria were based on a previous clinical trial ${ }^{19}$ : age $18-40$ years; insidious onset of anterior knee or retropatellar pain of greater than six weeks' duration and provoked by at least two of prolonged sitting or kneeling, squatting, running, hopping, or stair walking; tenderness on palpation of the patella, or pain with step down or double leg squat; and worst pain over the previous week of at least $30 \mathrm{~mm}$ on a $100 \mathrm{~mm}$ visual analogue scale. Exclusion criteria were concomitant injury or pain from the hip, lumbar spine, or other knee structures; previous knee surgery; patellofemoral instability; knee joint effusion; any foot condition that precluded use of foot orthoses; allergy to strapping tape; use of physiotherapy or foot orthoses within the previous year; or use of anti-inflammatory drugs.

\section{Protocol}

To facilitate concealment of allocation, a blinded assessor not involved in the randomisation process determined eligibility. The randomisation sequence was drawn up and kept off site by an independent body, using a random number generator in blocks of eight with no stratification. Participants gave written informed consent and, after we had obtained baseline measures, were randomly assigned to receive one of four treatments: foot orthoses, flat inserts, physiotherapy, or foot orthoses plus physiotherapy. A research assistant communicated with the randomisation centre, participants, and project physiotherapists throughout the trial, thus ensuring that the assessor responsible for outcome measurement and data analysis remained blind to group allocation.

\section{Interventions}

Interventions were administered by one of 17 registered physiotherapists who underwent training for each treatment protocol. Participants attended six appointments of 20-60 minutes' duration over six weeks, after which they were encouraged to continue with a self management programme.

The intervention programmes have been detailed previously. ${ }^{25}$ In brief, participants assigned to foot orthoses received prefabricated, commercially available orthoses (Vasyli International), which were fitted to their shoes with comfort as a primary goal. These orthoses are customisable to some degree to optimise comfort through heat moulding and by adding wedge or heel raises. As a control for these orthoses we used flat inserts, manufactured from the same material (ethylenevinyl acetate) with identical covering fabric. These were of uniform thickness, with no inbuilt arch or wedging. Physiotherapy consisted of a combined 
Table 1| Baseline characteristics of participants for intervention groups and study cohort. Values are mean (SD) unless stated otherwise

\begin{tabular}{|c|c|c|c|c|c|}
\hline Characteristics & $\begin{array}{l}\text { Foot orthoses } \\
\qquad(n=46)\end{array}$ & $\begin{array}{l}\text { Flat inserts } \\
\qquad(n=44)\end{array}$ & $\begin{array}{l}\text { Physiotherapy } \\
(n=45)\end{array}$ & $\begin{array}{l}\text { Foot orthoses plus } \\
\text { physiotherapy }(n=44)\end{array}$ & Total $(n=179)$ \\
\hline Age (years) & $27.9(5.3)$ & $29(6.0)$ & $30.9(5.8)$ & $29.6(5.6)$ & $29.3(5.8)$ \\
\hline No (\%) of women & $25(54.3)$ & $20(45.5)$ & $29(64.4)$ & $26(59.1)$ & $100(55.9)$ \\
\hline Height (cm) & $172.8(9.1)$ & $174.9(10.5)$ & $170.9(8.4)$ & $173.3(9.6)$ & $173(9.5)$ \\
\hline Weight (kg) & $78.5(20.4)$ & $73.8(15.9)$ & $70.9(14.6)$ & $75.2(22.3)$ & $74.7(18.6)$ \\
\hline Body mass index & $26.1(5.6)$ & $23.9(3.5)$ & $24.2(4.7)$ & $24.8(6.2)$ & $24.8(5.1)$ \\
\hline Physical activity* (kcal/kg) & $40.6(7.1)$ & $41.3(7)$ & $41.2(7.3)$ & $40.8(8.1)$ & $41(7.3)$ \\
\hline No (\%) with bilateral knee pain & $26(56.5)$ & $25(56.8)$ & $26(57.8)$ & $25(56.8)$ & $102(57)$ \\
\hline $\begin{array}{l}\text { Median (interquartile range) duration } \\
\text { of knee pain (months) }\end{array}$ & $42(12.3-96)$ & $24(12-71)$ & $37(12.3-84.8)$ & $24(9-60)$ & $28(12-84)$ \\
\hline Usual pain† & $38.6(16)$ & $32.8(15.1)$ & $34.1(17.0)$ & $39.8(17.6)$ & $36.3(16.6)$ \\
\hline Worst pain $†$ & $59.4(15.3)$ & $56.6(14.9)$ & $61.4(15.6)$ & $64.8(17.0)$ & $60.5(15.9)$ \\
\hline Anterior knee pain scale $\ddagger$ & $70.8(9.0)$ & $72.1(9.3)$ & $71.7(11.3)$ & $71.5(9.8)$ & $71.5(9.8)$ \\
\hline Functional index questionnaire§ & $10(1.9)$ & $10(1.9)$ & $10(2.6)$ & $9.3(2.0)$ & $9.8(2.1)$ \\
\hline
\end{tabular}

*Physical activity over previous week questionnaire, total energy expended per day.

†Pain measured on $100 \mathrm{~mm}$ visual analogue scale; $0 \mathrm{~mm}=$ no pain, $100 \mathrm{~mm}=$ worst pain imaginable.

$\ddagger 0-100$ points; $100=$ no disability.

§0-16 points; $16=$ no disability.

therapy approach that has proved efficacious in patellofemoral pain syndrome ${ }^{19}$ and included patellar mobilisation, patellar taping, a progressive programme of vasti muscle retraining exercises with electromyographic biofeedback, hamstring and anterior hip stretches, hip external rotator retraining, and a home exercise programme. Participants assigned to orthoses plus physiotherapy received both interventions as described and had an extra appointment with the physiotherapist if more time was required for adequate delivery of all treatment components.

The participants were encouraged to continue exercise and activities that did not provoke their pain. The use of non-study interventions was discouraged throughout the trial, although over the counter drugs were permitted. Any cointerventions used for symptoms of patellofemoral pain syndrome, as well as any adverse effects arising from intervention, were recorded in diaries, reported to the research assistant, or detailed in an exit questionnaire.

\section{Outcomes}

The blinded assessor carried out reliable and valid outcome measures ${ }^{2526}$ before randomisation (baseline) and at 6,12 , and 52 weeks after randomisation. The primary outcome measures were global improvement, ${ }^{25}$ severity of usual and worst pain over the preceding week, the anterior knee pain scale, ${ }^{27}$ and the functional index questionnaire. ${ }^{28} \mathrm{We}$ measured global improvement on a five point Likert scale ("marked improvement" to "marked worsening") and visual analogue scale $(-100 \mathrm{~mm}=$ much worse, $0=$ same, $100=$ completely better). We reduced categorical data to success equating marked or moderate improvement. ${ }^{19}$

\section{Sample size}

We based the sample size calculations on a clinically meaningful improvement of $15 \mathrm{~mm}$ on a $100 \mathrm{~mm}$ pain visual analogue scale for usual pain. ${ }^{2629}$ Assuming a standard deviation of $20 \mathrm{~mm},{ }^{19}$ a power of 0.80 , and an $\alpha$ level of 0.01 , we required 40 participants in each group. We increased the sample size by $10 \%$, to 176 (44 in each group), to allow for loss to follow-up.

\section{Statistical analysis}

Statistical analysis was done on a blinded, intention to treat basis using SPSS software (version 15.0). We chose the primary end points of 6,12 , and 52 weeks, as six weeks (immediately after the treatment period) could be considered to be the time of greatest effect, 12 weeks is a standard follow-up time in studies of patellofemoral pain syndrome,$^{30-33}$ and the long term (52 weeks) efficacy of foot orthoses or this specific physiotherapy programme has not been investigated. The dichotomous measure of success was expressed as relative risk reduction and numbers needed to treat. We analysed continuous outcome measures using univariate analysis of covariance, with baseline as a covariate and group allocation as a fixed factor. We included the characteristics of the participants and other baseline outcome measures as covariates in statistical models to determine their impact on outcome. Significance was set at 0.01 to accommodate the possibility of an inflated type I error rate resulting from multiple comparisons.

\section{RESULTS}

From May 2004 to May 2006, 1530 volunteers were screened and 179 enrolled in the study (fig 1). The trial was completed in June 2007, with 164 participants $(92 \%)$ followed up at six weeks, $161(90 \%)$ at 12 weeks, and $171(96 \%)$ at 52 weeks. With the exception of duration, all groups were well matched at baseline (table 1). Including baseline data as covariates did not significantly influence outcomes.

Significant effects favoured foot orthoses over flat inserts at six weeks, with differences of $19.8 \mathrm{~mm}(99 \%$ 


\begin{tabular}{|c|c|c|c|c|c|c|c|}
\hline \multirow[b]{2}{*}{ Follow-up } & \multicolumn{4}{|c|}{ No (\%) moderately or markedly improved* } & \multicolumn{3}{|c|}{ Between group differences $(99 \% \mathrm{Cl}) \dagger$} \\
\hline & Foot orthoses & Flat inserts & Physiotherapy & $\begin{array}{l}\text { Foot orthoses plus } \\
\text { physiotherapy }\end{array}$ & $\begin{array}{c}\text { Foot orthoses } \\
v \text { flat inserts }\end{array}$ & $\begin{array}{c}\text { Physiotherapy } v \text { foot } \\
\text { orthoses }\end{array}$ & $\begin{array}{c}\text { Foot orthoses plus } \\
\text { physiotherapy } v \\
\text { physiotherapy }\end{array}$ \\
\hline 6 weeks & $35 / 41(85)$ & $23 / 40(58)$ & 38/41 (93) & $38 / 42(90)$ & $\begin{array}{l}0.66(0.05 \text { to } 1.17) \ddagger ; \\
\text { NNT } 4(2 \text { to } 51) \ddagger \dagger\end{array}$ & $\begin{array}{l}0.5(-0.84 \text { to } 1.85) ; \\
\text { NNT } 14 \text { ( }-8 \text { to } 4)\end{array}$ & $\begin{array}{c}-0.3(-2.83 \text { to } 2.24) ; \\
\text { NNT }-45(-5 \text { to } 6)\end{array}$ \\
\hline 12 weeks & $34 / 42(81)$ & $30 / 38(79)$ & $34 / 41(83)$ & $38 / 40(95)$ & $\begin{array}{l}0.1(-0.99 \text { to } 1.2) \\
\text { NNT } 50(-5 \text { to } 4)\end{array}$ & $\begin{array}{l}0.1(-1.06 \text { to } 1.25) ; \\
\text { NNT } 51 \text { ( }-5 \text { to } 4)\end{array}$ & $\begin{array}{l}0.71(-0.44 \text { to } 1.87) ; \\
\text { NNT } 8(-13 \text { to } 3)\end{array}$ \\
\hline 52 weeks & $38 / 45(84)$ & $30 / 41(73)$ & $34 / 42(81)$ & $35 / 43(81)$ & $\begin{array}{l}0.42(-0.43 \text { to } 1.24) ; \\
\text { NNT } 9 \text { ( }-9 \text { to } 3)\end{array}$ & $\begin{array}{c}-0.22(-1.6 \text { to } 1.14) \\
\text { NNT }-29(-4 \text { to } 6)\end{array}$ & $\begin{array}{l}0.02(-1.13 \text { to } 1.18) ; \\
\text { NNT } 226(-5 \text { to } 4)\end{array}$ \\
\hline
\end{tabular}

*Participants rated improvement on five point Likert scale of global effect.

†Positive point estimate favours first listed condition.

$\ddagger$ Significant at $\mathrm{P}=0.01$.

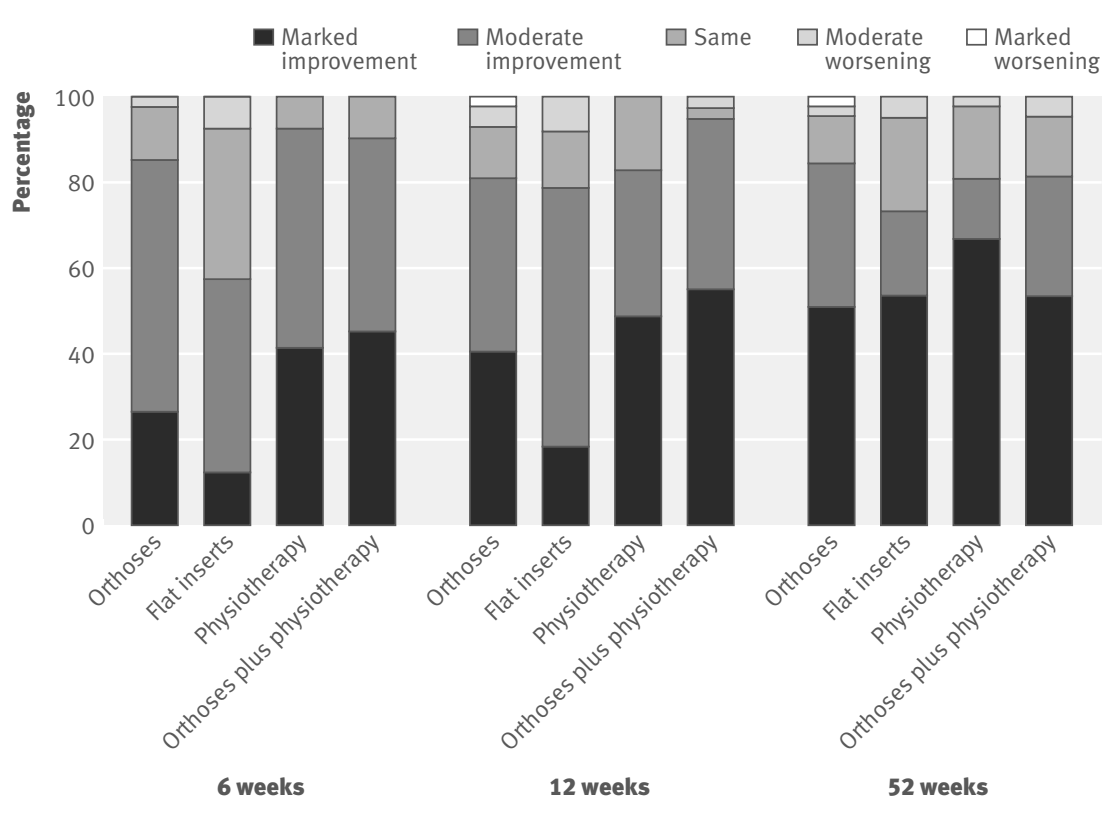

Fig 2 | Percentage of participants rating perceived improvement across categories from marked improvement to marked worsening orthoses, physiotherapy, foot orthoses plus physiotherapy) also had clinically meaningful improvements in usual pain severity, whereas the improvement in usual pain for the group receiving flat inserts was slightly less than $20 \mathrm{~mm}$. No significant differences were found between groups on any primary measure at 52 weeks.

\section{Cointerventions}

Table 4 outlines the participants' use of cointerventions. No significant differences were found in reported rates of use between foot orthoses and flat inserts (14/ $40,35 \%$ v 15/39, 38\%; relative risk reduction $0.09,99 \%$ confidence interval -0.6 to 0.76 ), physiotherapy and foot orthoses $(16 / 43,37 \%$ v $14 / 40,35 \% ;-0.06,-0.78$ to 0.68 ), or foot orthoses plus physiotherapy and physiotherapy alone $(9 / 40,23 \% v 16 / 43,37 \% ; 0.4,-0.3$ to 1.01). Two participants assigned to flat inserts crossed over to foot orthoses after 12 weeks.

\section{Side effects}

A greater proportion of participants reported mild side effects with the foot orthoses (foot orthoses $31 / 43,72 \%$; foot orthoses plus physiotherapy $20 / 41,49 \%$ ) than with the flat inserts $(15 / 39,38 \%$; relative risk reduction $-0.58,99 \%$ confidence interval -1.01 to -0.09 ). These consisted of rubbing and blistering, discomfort, and pain in the toes, feet, and ankles, which on the whole responded to increasing wear and minor adjustments to the orthoses (for example, heat moulding and additions) and did not prevent wearing of the orthoses or inserts. Thirty four participants (physiotherapy 18/ $44,41 \%$; foot orthoses plus physiotherapy $16 / 41,39 \%$; relative risk reduction $0.05,-0.59$ to 0.67 ) reported a reaction to daily patellar taping (for example, skin irritation, blistering). Two participants (physiotherapy group and foot orthoses group) experienced low back pain that required additional physiotherapy.

\section{DISCUSSION}

Foot orthoses produced short term improvements beyond that of flat inserts, with the number needed to treat indicating that four patients would need to be treated with orthoses to have one additional patient experience improvement in patellofemoral pain. Foot 
orthoses were similar in effect to physiotherapy, and combining foot orthoses with physiotherapy did not provide additional improvement beyond physiotherapy alone. In the long term, clinically meaningful improvements occurred in pain and function for all interventions but no differences were found between interventions. The overall pattern of effect implies that foot orthoses and physiotherapy each hasten resolution of the condition, which is an important benefit for a common, chronic condition.

Treatment costs are a further consideration for practitioners and their patients. Assuming recommended retail pricing, in addition to consultation fees (usually between two to four consultations), the orthoses (three pairs, including additions) would cost \$A174 (£79; €100) compared with \$A45 for three flat inserts. This would seem to be a reasonable alternative to physiotherapy (six sessions at around \$A495, including tape). A cost benefit analysis is required to investigate this further.

The interventions used in this trial, including the flat inserts, produced only mild side effects in the early phase of treatment. Despite the orthoses having relatively more minor side effects than the flat inserts, they showed a greater improvement in the first six weeks, suggesting that these side effects did not adversely influence treatment outcomes. About 40\% of participants who received the physiotherapy intervention (with or without foot orthoses) experienced skin reactions with daily taping of the patella, despite exclusion of participants with known allergies to tape. It is difficult to know whether this is abnormally high due to inadequate reporting in previous trials, but should be considered in clinical application.

The prescription of foot orthoses for musculoskeletal pain is characterised by a lack of evidence from high quality clinical trials. ${ }^{1520}$ Our study provided level II evidence for the use of foot orthoses in patellofemoral pain syndrome. Our data corroborate findings from a smaller study of 20 adolescent females aged 13 to 17 , which found statistically significant improvements in pain during gait, sitting, and squatting after eight weeks of treatment. ${ }^{21}$ The authors did not supply point estimates of effect. Furthermore, the magnitude of the effect of physiotherapy that we observed on primary outcome measures at six weeks was comparable with that of another study. ${ }^{19}$

Some authors contend that the contoured form of foot orthoses is critical for controlling foot motion, usually excessive pronation. ${ }^{34-36}$ This exists despite three key issues, all of which impinge on the conduct of a randomised controlled trial. Firstly, research shows generally equivocal and non-systematic effects of the ability of foot orthoses to control motion. ${ }^{37-39}$ Secondly, alternative means may be available by which foot orthoses exert clinical effects, such as by serving as space fillers to facilitate full plantar contact, ${ }^{40}$ which some regard to be clinically beneficial. ${ }^{4142}$ Thirdly, previous research has failed to show that people with patellofemoral pain syndrome have excessive foot

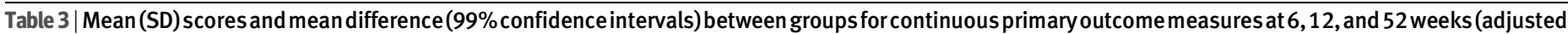
for baseline), according to intervention for patellofemoral pain syndrome

\begin{tabular}{|c|c|c|c|c|c|c|c|}
\hline \multirow[b]{2}{*}{ Variables } & \multicolumn{4}{|c|}{ Mean (SD) for each group } & \multicolumn{3}{|c|}{ Mean $(99 \% \mathrm{Cl})$ differences between groups } \\
\hline & Foot orthoses & Flat inserts & Physiotherapy & $\begin{array}{l}\text { Foot orthoses } \\
\text { plus } \\
\text { physiotherapy }\end{array}$ & $\begin{array}{l}\text { Foot orthoses } v \text { flat } \\
\text { inserts }\end{array}$ & $\begin{array}{c}\text { Physiotherapy } v \\
\text { foot orthoses }\end{array}$ & $\begin{array}{c}\text { Foot orthoses plus } \\
\text { physiotherapy } v \\
\text { physiotherapy }\end{array}$ \\
\hline \multicolumn{8}{|c|}{ Global improvement (-100-100)*: } \\
\hline 6 weeks & $37.6(27.2)$ & $17.8(27.2)$ & $45.4(27.2)$ & $48.7(27.2)$ & 19.8 (4.0 to 35.6$) \dagger$ & $7.8(-7.8$ to 23.5$)$ & $3.2(-12.3$ to 18.8$)$ \\
\hline 12 weeks & $46.7(32.8)$ & $30.6(32.8)$ & $53.4(32.8)$ & $61.8(32.8)$ & $16.1(-3.0$ to 35.3$)$ & $6.7(-12.1$ to 25.5$)$ & $8.4(-10.7$ to 27.4$)$ \\
\hline 52 weeks & $52.3(39.8)$ & $49.9(39.8)$ & $54.7(39.8)$ & $55.2(39.8)$ & 2.4 (-20.0 to 24.8$)$ & $2.4(-19.9$ to 24.7$)$ & $0.5(-22.0$ to 23.0$)$ \\
\hline \multicolumn{8}{|c|}{ Usual pain (0-100 mm)‡: } \\
\hline 6 weeks & $25.4(17.4)$ & $33.4(17.5)$ & $21.2(17.3)$ & $19.4(17.4)$ & $-8(-18.1$ to 2.1$)$ & $-4.2(-14.2$ to 5.8$)$ & $-1.8(-11.8$ to 8.2$)$ \\
\hline 12 weeks & $22.1(17.8)$ & $24.5(18)$ & $20.1(17.8)$ & $16.4(17.9)$ & $-2.4(-12.9$ to 8.1$)$ & $-2(-12.2$ to 8.2$)$ & $-3.7(-14.1$ to 6.6$)$ \\
\hline 52 weeks & $16.2(18.5)$ & $17.9(18.6)$ & $13.9(18.5)$ & $14.4(18.6)$ & $-1.7(-12.2$ to 8.8$)$ & $-2.2(-12.6$ to 8.1$)$ & $0.4(-10.1$ to 10.9$)$ \\
\hline \multicolumn{8}{|c|}{ Worst pain $(0-100 \mathrm{~mm}) \ddagger:$} \\
\hline 6 weeks & $39.8(21.7)$ & $48(21.8)$ & $32.2(21.6)$ & $28.5(21.9)$ & $-8.1(-20.7$ to 4.4$)$ & $-7.7(-20.2$ to 4.8$)$ & $-3.6(-16.0$ to 8.8$)$ \\
\hline 12 weeks & $33.3(22.2)$ & $35(22.4)$ & $26.8(22.2)$ & $26.5(22.3)$ & $-1.7(-14.7$ to 11.3$)$ & $-6.5(-19.2$ to 6.2$)$ & $-0.2(-13.1$ to 12.7$)$ \\
\hline 52 weeks & $27.6(23.7)$ & $26.1(23.9)$ & $22.2(23.7)$ & $18.8(23.9)$ & $1.5(-11.9$ to 15.0$)$ & $-5.5(-18.8$ to 7.9$)$ & $-3.3(-16.8$ to 10.1$)$ \\
\hline \multicolumn{8}{|c|}{ Anterior knee pain scale $(0-100)^{\star}$ : } \\
\hline 6 weeks & $79.7(9.1)$ & $74.8(9.1)$ & $83.4(9.1)$ & $83.6(9.1)$ & $4.9(-0.4$ to 10.2$)$ & $3.7(-1.6$ to 9.0$)$ & $0.2(-5.0$ to 5.5$)$ \\
\hline 12 weeks & $81.8(9.9)$ & $80.9(9.9)$ & 84.9 (9.9) & $86.7(9.9)$ & $0.9(-4.9$ to 6.6$)$ & $3.1(-2.5$ to 8.8$)$ & $1.8(-4.0$ to 7.5$)$ \\
\hline 52 weeks & $85.5(9.7)$ & $86.9(9.7)$ & $87.9(9.7)$ & $91.5(9.7)$ & $-1.5(-7.3$ to 4.4$)$ & $2.5(-3.3$ to 8.2$)$ & $3.6(-2.5$ to 9.7$)$ \\
\hline \multicolumn{8}{|c|}{ Functional index questionnaire $(0-16)^{\star}$ : } \\
\hline 6 weeks & $11.8(2.3)$ & $11.1(2.3)$ & $12.9(2.3)$ & $13.3(2.3)$ & $0.7(-0.6$ to 2.0$)$ & $1.0(-0.3$ to 2.3$)$ & $0.5(-0.8$ to 1.8$)$ \\
\hline 12 weeks & $12.3(2.3)$ & $12.0(2.3)$ & $13.3(2.3)$ & $13.9(2.3)$ & $0.2(-1.1$ to 1.6$)$ & $1.0(-0.3$ to 2.4$)$ & $0.6(-0.8$ to 1.9$)$ \\
\hline 52 weeks & $13.0(2.6)$ & $13.4(2.6)$ & $14.2(2.6)$ & $13.8(2.6)$ & $-0.5(-1.9$ to 1.0$)$ & $1.3(-0.2$ to 2.7$)$ & $-0.5(-1.9$ to 1.0$)$ \\
\hline
\end{tabular}

*Positive score favours reference group (first group listed in comparison). 


\begin{tabular}{|c|c|c|c|c|c|}
\hline Additional intervention & $\begin{array}{l}\text { Foot orthoses } \\
\qquad(n=40)\end{array}$ & Flat inserts $(n=39)$ & $\begin{array}{l}\text { Physiotherapy } \\
\qquad(n=43)\end{array}$ & $\begin{array}{l}\text { Foot orthoses plus } \\
\text { physiotherapy }(n=40)\end{array}$ & Total $(n=162)$ \\
\hline None & 26 & 24 & 27 & 31 & 108 \\
\hline General practitioner or specialist & 3 & 0 & 0 & 1 & 4 \\
\hline Physiotherapy & 3 & 1 & 1 & 2 & 7 \\
\hline Foot orthoses & 0 & $3 \dagger$ & 1 & 0 & 4 \\
\hline Massage & 1 & 0 & 1 & 0 & 2 \\
\hline Over counter drugs $\ddagger$ & 11 & 12 & 13 & 7 & 43 \\
\hline Prescription drugs $\ddagger$ & 0 & 1 & 0 & 0 & 1 \\
\hline Acupuncture & 1 & 0 & 0 & 1 & 2 \\
\hline Complementary medicine & 1 & 2 & 3 & 2 & 8 \\
\hline Heat rub & 1 & 0 & 1 & 1 & 3 \\
\hline Ice or heat & 4 & 0 & 1 & 1 & 6 \\
\hline Knee brace & 1 & 0 & 0 & 1 & 2 \\
\hline
\end{tabular}

*Some participants used more than one additional intervention.

tIncludes two participants who crossed over to receive foot orthoses after 12 weeks as recommended by trial physiotherapists.

$\ddagger$ Analgesics and non-steroidal anti-inflammatory drugs.

pronation compared with controls. ${ }^{1043}$ On the basis of these issues, we included in our randomised controlled trial a flat shoe insert to evaluate the clinical efficacy of the contoured form of foot orthoses. ${ }^{25}$ Our findings of a clinically beneficial effect in favour of the contoured orthoses provides a solid foundation on which to consider the mechanisms of action of foot orthoses and plan future research.

Point estimates of effect between foot orthoses and flat inserts were detected by using measures of global improvement, but not by using measures of pain or physical function, even though these measures were sensitive to change over time within each group. This reflects the moderate correlations between global improvement rating scales and these measures of pain and function reported by researchers ${ }^{26}$ in their evaluation of outcome measures used in their randomised controlled trial. ${ }^{19}$ They recommended that clinical trials of patellofemoral pain syndrome incorporate a measure of perceived global response to treatment, largely on the basis that this scale feasibly encompasses many dimensions of patellofemoral pain syndrome that are meaningful to the patient (for example, pain, function, disability, participation, psychosocial factors). It is likely that a rating of global improvement captures more comprehensively the patient experience, a notion that requires further exploration to understand better the clinical relevance.

\section{Strengths and limitations}

The prescription of foot orthoses for musculoskeletal pain is characterised by a lack of solid evidence from quality clinical trials. ${ }^{20}$ We studied the long term efficacy of foot orthoses in the management of patellofemoral pain syndrome. This is a clinically important issue as the condition is highly prevalent and foot orthoses are prescribed worldwide. We incorporated the recommendations from the consolidated standards of reporting trials into the methodological design, which further strengthens the validity of findings. ${ }^{44}$ Importantly, the attrition rate was low, with $8 \%$ of primary outcome data missing at six weeks, $10 \%$ at 12 weeks, and $4 \%$ at 52 weeks.

Unlike other clinical trials, we did not select those treated with foot orthoses on the basis of foot posture (for example, excessive pronation ${ }^{22}$ ), largely because no valid method currently exists to identify a priori those who may benefit from foot orthoses. It is possible that participants fitted with orthoses in our trial were (randomly) heterogeneous for foot posture, yet we still found small but beneficial effects of prescribing foot orthoses compared with flat inserts. Conceivably, if the classification of patients becomes possible,${ }^{45}$ then the point estimates of effect we report are likely to be an underestimate.

The characteristics of the participants in our trial were similar to those reported by others for age, height, sex, proportion with bilateral patellofemoral pain syndrome, duration of condition, severity of pain, anterior knee pain scale, and functional index questionnaire..$^{10193033}$ Feasibly this represents the broader population of patients with patellofemoral pain syndrome who visit general medical practices and strengthens the external validity of the findings of our study. Further reinforcing the external validity of our findings we used physiotherapists from primary care practices in the community, and with only a short duration of training in the protocol (about 1.5 days) they were able to successfully implement an effective foot orthosis intervention, which had a similar effect to the multimodal physiotherapy programme.

A limitation of this study is the number of comparisons between groups. Although we used 99\% confidence limit to assist in control of type I errors, it is possible that the significant finding between foot orthoses and flat inserts was due to chance. Notwithstanding this, a number needed to treat of 4 could be regarded as a clinically meaningful effect and in part counters the possibility of a type I error in the comparison of orthoses with flat inserts at six weeks.

A further limitation was that we did not include a control group for clinical course so we cannot 


\section{WHAT IS ALREADY KNOWN ON THIS TOPIC}

Patellofemoral pain syndrome is highly prevalent in sports medicine and presents often to general practices

Foot orthoses are often prescribed despite a lack of evidence highlighted by systematic reviews

\section{WHAT THIS STUDY ADDS}

Foot orthoses produce earlier and larger improvements in patellofemoral pain syndrome than flat inserts

Adding foot orthoses to physiotherapy does not improve physiotherapy outcomes

decisively conclude that foot orthoses or physiotherapy were better than no treatment over 52 weeks. Nevertheless, a case may be made for intervening with foot orthoses or physiotherapy as over $80 \%$ of participants in our study were improved at 52 weeks, compared with $50 \%$ of participants followed up at four years in a prospective long term study of the clinical course of patellofemoral pain syndrome. ${ }^{11}$

\section{Conclusions}

Prefabricated foot orthoses are superior to flat inserts in the short term management of patellofemoral pain syndrome, implying that their contoured shape is therapeutic. We found no differences between the effects of foot orthoses and physiotherapy, nor was there any benefit of adding foot orthoses to physiotherapy. Considering that all treatment groups showed clinically meaningful long term improvements, general practitioners may seek to hasten recovery by prescribing foot orthoses.

We thank Vasyli International for providing the foot orthoses and flat inserts; Ausmedic and Access Health for supplying concessions on the purchase of equipment used in the physiotherapy interventions; the project physiotherapists and their practice staff; Jenny McConnell for her assistance in running the protocol workshops; and research assistants Jane Buckley, Bula Elwell, and Erica Williams.

Contributors: NC recruited and screened the participants, carried out the baseline and follow-up outcome measures and data entry and analysis, and prepared the manuscript. KC was involved in the methodological design and preparation of the manuscript. EB assisted in the trial design and carried out the randomisation procedures. RD advised on the statistical design of the trial and data analysis and interpretation. TM was involved in the National Health and Medical Research Council grant application and trial design and reviewed the manuscript. BV, in his capacity as sole chief investigator on the National Health and Medical Research Council grant, supervised the conduct of the trial, the suitability of included participants, data analysis, and preparation of the manuscript, and is guarantor.

Funding: This trial was funded primarily by the National Health and Medical Research Council of Australia (primary health care project grant No 301037). NC was the recipient of a National Health and Medical Research Council of Australia public health scholarship (No 351663). Vasyli International donated the foot orthoses and flat inserts. The work of the authors was independent of the funders.

Competing interests: BV has been reimbursed by Vasyli International for seminar presentations and has also received research funding from this company.

Ethical approval: University of Queensland's medical research ethics committee.

Provenance and peer review: Not commissioned; externally peer reviewed.

1 Australian Acute Musculoskeletal Pain Guidelines Group. Evidencebased management of acute musculoskeletal pain. Brisbane: Australian Academic Press, 2003.
2 Van Middelkoop M, van Linschoten R, Berger MY, Koes BW, Bierma-Zeinstra SM. Knee complaints seen in general practice: active sport participants versus non-sport participants. BMC Musculoskelet Disord 2008;9:36.

3 Ballas MT, Tytko J, Cookson D. Common overuse running injuries: diagnosis and management. Am Fam Physician 1997;55:2473-84.

4 Baquie $P$, Brukner P. Injuries presenting to an Australian sports medicine centre: a 12-month study. Clin / Sport Med 1997;7:28-31.

5 Clement DB, Taunton SE, Smart GW, McNicol KL. A survey of overuse running injuries. Phys Sportsmed 1981;9:47-58.

6 DeHaven KE, Lintner DM. Athletic injuries: comparison by age, sport, and gender. Am / Sports Med 1986;14:218-24.

7 Devereaux MD, Lachmann SM. Patello-femoral arthralgia in athletes attending a sports injury clinic. Br J Sports Med 1984;18:18-21.

8 Matheson GO, Macintyre JG, Taunton JE, Clement DB, Lloyd-Smith R. Musculoskeletal injuries associated with physical activity in older adults. Med Sci Sports Exerc 1989;21:379-85

9 Taunton JE, Ryan MB, Clement DB, McKenzie DC, Lloyd-Smith DR, Zumbo BD. A retrospective case-control analysis of 2002 running injuries. Br J Sports Med 2002;36:95-101.

10 Witvrouw E, Lysens R, Bellemans J, Cambier D, Vanderstraeten G. Intrinsic risk factors for the development of anterior knee pain in an athletic population. A two-year prospective study. Am J Sports Med 2000;28:480-9.

11 Nimon G, Murray D, Sandow M, Goodfellow J. Natural history of anterior knee pain: a 14- to 20-year follow-up of nonoperative management. J Pediatr Orthop 1998;18:118-22.

12 Arroll B, Ellis-Pegler E, Edwards A, Sutcliffe G. Patellofemoral pain syndrome: a critical review of the clinical trials on nonoperative therapy. Am J Sports Med 1997;25:207-12.

13 Bizzini M, Childs JD, Piva SR, Delitto A. Systematic review of the quality of randomized controlled trials for patellofemoral pain syndrome.J Orthop Sports Phys Ther 2003;33:4-20.

14 Brosseau L, Casimiro L, Robinson V, Milne S, Shea B, Judd M, et al. Therapeutic ultrasound for treating patellofemoral pain syndrome. Cochrane Database Syst Rev 2001;(4):CD003375.

15 Crossley K, Bennell K, Green S, McConnell J. A systematic review of physical interventions for patellofemoral pain syndrome. Clin J Sport Med 2001;11:103-10.

16 D'Hondt NE, Struijs PA, Kerkhoffs GM, Verheul C, Lysens R, Aufdemkampe G, et al. Orthotic devices for treating patellofemoral pain syndrome. Cochrane Database Syst Rev 2002;(2):CD002267.

17 Heintjes E, Berger MY, Bierma-Zeinstra SM, Bernsen RM, Verhaar JA, Koes BW. Exercise therapy for patellofemoral pain syndrome. Cochrane Database Syst Rev 2003;(4):CD003472.

18 McConnell J. The physical therapist's approach to patellofemoral disorders. Clin Sports Med 2002;21:363-87.

19 Crossley K, Bennell K, Green S, Cowan S, McConnell J. Physical therapy for patellofemoral pain: a randomized, double-blinded, placebocontrolled trial. Am J Sports Med 2002;30:857-65.

20 Collins N, Bisset L, McPoil T, Vicenzino B. Foot orthoses in lower limb overuse conditions: a systematic review and meta-analysis. Foot Ankle Int 2007;28:396-412.

21 Eng JJ, Pierrynowski MR. Evaluation of soft foot orthotics in the treatment of patellofemoral pain syndrome. Phys Ther 1993;73:62-8; discussion 68-70.

22 Wiener-Ogilvie S, Jones RB. A randomised trial of exercise therapy and foot orthoses as treatment for knee pain in primary care. Br J Podiatry 2004;7:43-9.

23 McPoil TG, Hunt GC. Evaluation and management of foot and ankle disorders: present problems and future directions. J Orthop Sports Phys Ther 1995;21:381-8.

24 Nigg BM, Nurse MA, Stefanyshyn DJ. Shoe inserts and orthotics for sport and physical activities. Med Sci Sports Exerc 1999;31(7 suppl):S421-8

25 Vicenzino B, Collins N, Crossley K, Beller E, Darnell R, McPoil T. Foot orthoses and physiotherapy in the treatment of patellofemoral pain syndrome: a randomised clinical trial. BMC Musculoskelet Disord 2008;9:27.

26 Crossley KM, Bennell KL, Cowan SM, Green S. Analysis of outcome measures for persons with patellofemoral pain: which are reliable and valid? Arch Phys Med Rehabil 2004;85:815-22.

27 Kujala UM, Jaakkola LH, Koskinen SK, Taimela S, Hurme M, Nelimarkka O. Scoring of patellofemoral disorders. Arthroscopy 1993;9:159-63.

28 Chesworth BM, Culham EG, Tata GE, Peat M. Validation of outcome measures in patients with patellofemoral syndrome. J Orthop Sports Phys Ther 1989;10:302-8.

29 Salaffi F, Stancati A, Silvestri CA, Ciapetti A, Grassi W. Minimal clinically important changes in chronic musculoskeletal pain intensity measured on a numerical rating scale. Eur J Pain 2004;8:283-91.

30 Clark DI, Downing N, Mitchell J, Coulson L, Syzpryt EP, Doherty M. Physiotherapy for anterior knee pain: a randomised controlled trial. Ann Rheum Dis 2000;59:700-4. 
31 Harrison EL, Sheppard MS, McQuarrie AM. A randomized controlled trial of physical therapy treatment programs in patellofemoral pain syndrome. Physiother Can 1999;51:93-106.

32 Roush MB, Sevier TL, Wilson JK, Jenkinson DM, Helfst RH, Gehlsen GM, et al. Anterior knee pain: a clinical comparison of rehabilitation methods. Clin J Sport Med 2000;10:22-8.

33 Witvrouw E, Lysens R, Bellemans J, Peers K, Vanderstraeten G. Open versus closed kinetic chain exercises for patellofemoral pain. A prospective, randomized study. Am J Sports Med 2000;28:687-94.

34 American College of Foot and Ankle Orthopedics and Medicine. Prescription custom foot orthoses practice guidelines. Bethesda, MD: American College of Foot and Ankle Orthopedics and Medicine, 2004.

35 Australian Podiatry Council. Clinical guidelines for orthotic therapy provided by podiatrists. East Brunswick, Victoria: Australian Podiatry Council, 1998.

36 Subotnick SI. Orthotic foot control and the overuse syndrome. Phys Sportsmed 1975;3:75-9.

37 Eng JJ, Pierrynowski MR. The effect of soft foot orthotics on threedimensional lower-limb kinematics during walking and running. Phys Ther 1994;74:836-44.

38 Novick A, Kelley DL. Position and movement changes of the foot with orthotic intervention during the loading response of gait. J Orthop Sports Phys Ther 1990;11:301-12.
39 McCulloch MU, Brunt D, Vander Linden D. The effect of foot orthotics and gait velocity on lower limb kinematics and temporal events of stance. J Orthop Sports Phys Ther 1993;17:2-10.

40 Kogler GF, Solomonidis SE, Paul JP. In vitro method for quantifying the effectiveness of the longitudinal arch support mechanism of a foot orthosis. Clin Biomech (Bristol, Avon) 1995;10:245-52.

41 Cornwall MW, McPoil TG. Effect of rearfoot posts in reducing forefoot forces. A single-subject design. J Am Podiatr Med Assoc 1992;82:371-4.

42 Kogler GF, Solomonidis SE, Paul JP. Biomechanics of longitudinal arch support mechanisms in foot orthoses and their effect on plantar aponeurosis strain. Clin Biomech (Bristol, Avon) 1996;11:243-52.

43 Powers CM, Chen PY, Reischl SF, Perry J. Comparison of foot pronation and lower extremity rotation in persons with and without patellofemoral pain. Foot Ankle Int 2002;23:634-40.

44 Altman DG, Schulz KF, Moher D, Egger M, Davidoff F, Elbourne D, et al. The revised CONSORT statement for reporting randomized trials: explanation and elaboration. Ann Intern Med 2001;134:663-94.

45 Vicenzino B, Collins N, Cleland J, McPoil T. A clinical prediction rule for identifying patients with patellofemoral pain who are likely to benefit from foot orthoses: a preliminary determination. Br / Sports Med 26 Sep 2008. doi: 10.1136/bjsm.2008.052613.

Accepted: 6 August 2008 